Supporting Information for

\title{
Acetone hydrodeoxygenation over bifunctional metallic-acidic molybdenum carbide catalysts
}

\author{
Mark M. Sullivan and Aditya Bhan* \\ Department of Chemical Engineering and Materials Science \\ University of Minnesota - Twin Cities \\ 421 Washington Avenue SE \\ Minneapolis, Minnesota 55455 \\ $U S A$ \\ E-mail addresses: sulli931@umn.edu (M. M. Sullivan), abhan@umn.edu (A. Bhan).
}

* Corresponding author. 


\section{S.1. Propanal hydrodeoxygenation}

Propanal HDO experiments were performed as constant contact time and reactant partial pressures by varying reaction temperature as shown in Figure S1. A sequential carbonyl hydrogenation/alcohol dehydration pathway was observed as evinced by a lack of any significant propylene or propane formation until $\sim 50 \%$ propanal hydrogenation was reached. Propylene hydrogenation to propane to form the terminal stable product of this reaction pathway was also shown at the highest reaction rates as achieved by the highest reaction temperature of $476 \mathrm{~K}$.

HDO rates, calculated as the sum of propylene and propane formation rates, were used to calculate a propanal HDO apparent activation energy of $113 \mathrm{~kJ} \mathrm{~mol}^{-1}$ as shown in Figure S2. HDO rates used for this analysis were not differential and are only meant as an estimate of the nature of the active site. Figure $\mathrm{S} 3$ shows HDO rates as a function of propanal pressure, exhibiting a zero order dependence over a propanal pressure range of $0.1-2 \mathrm{kPa}$; this zero order dependence indicates a propanal saturated surface similar to that observed with acetone/IPA oxygenate feeds. 


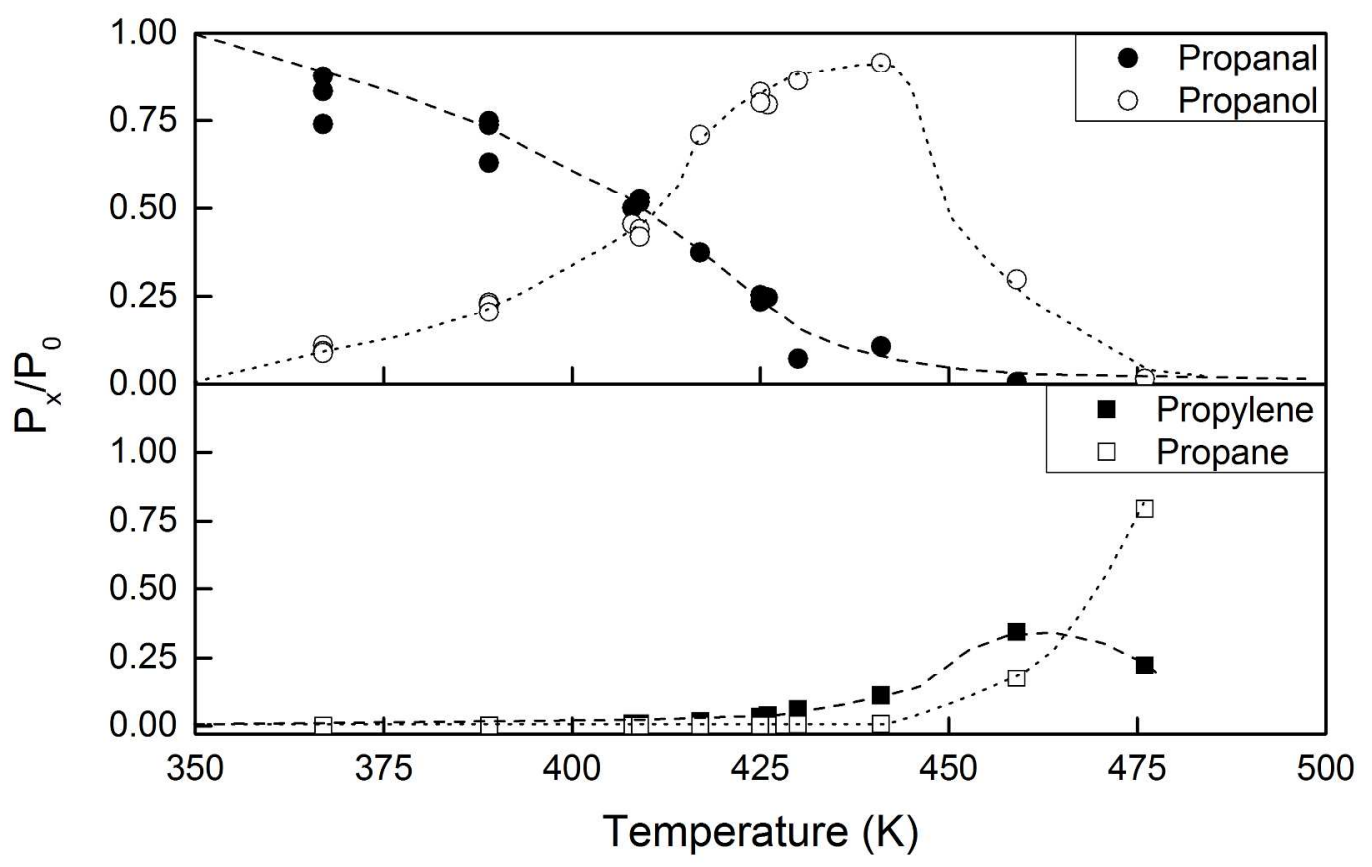

Figure S1. Normalized effluent partial pressures of reactants and products during propanal $\mathrm{HDO}$ reaction as a function of reaction temperature. $\mathrm{P}_{0}=0.26 \mathrm{kPa}$ pure propanal, $81 \mathrm{kPa} \mathrm{H}_{2}, 4 \mathrm{kPa} \mathrm{CH}_{4}$ as an internal standard, balance inert carrier gas, $\mathrm{T}=367$ $-476 \mathrm{~K}, 0.100 \mathrm{~g}_{\text {cat }}, \sim 110 \mathrm{~cm}^{3} \mathrm{~min}^{-1}$ total flow. 


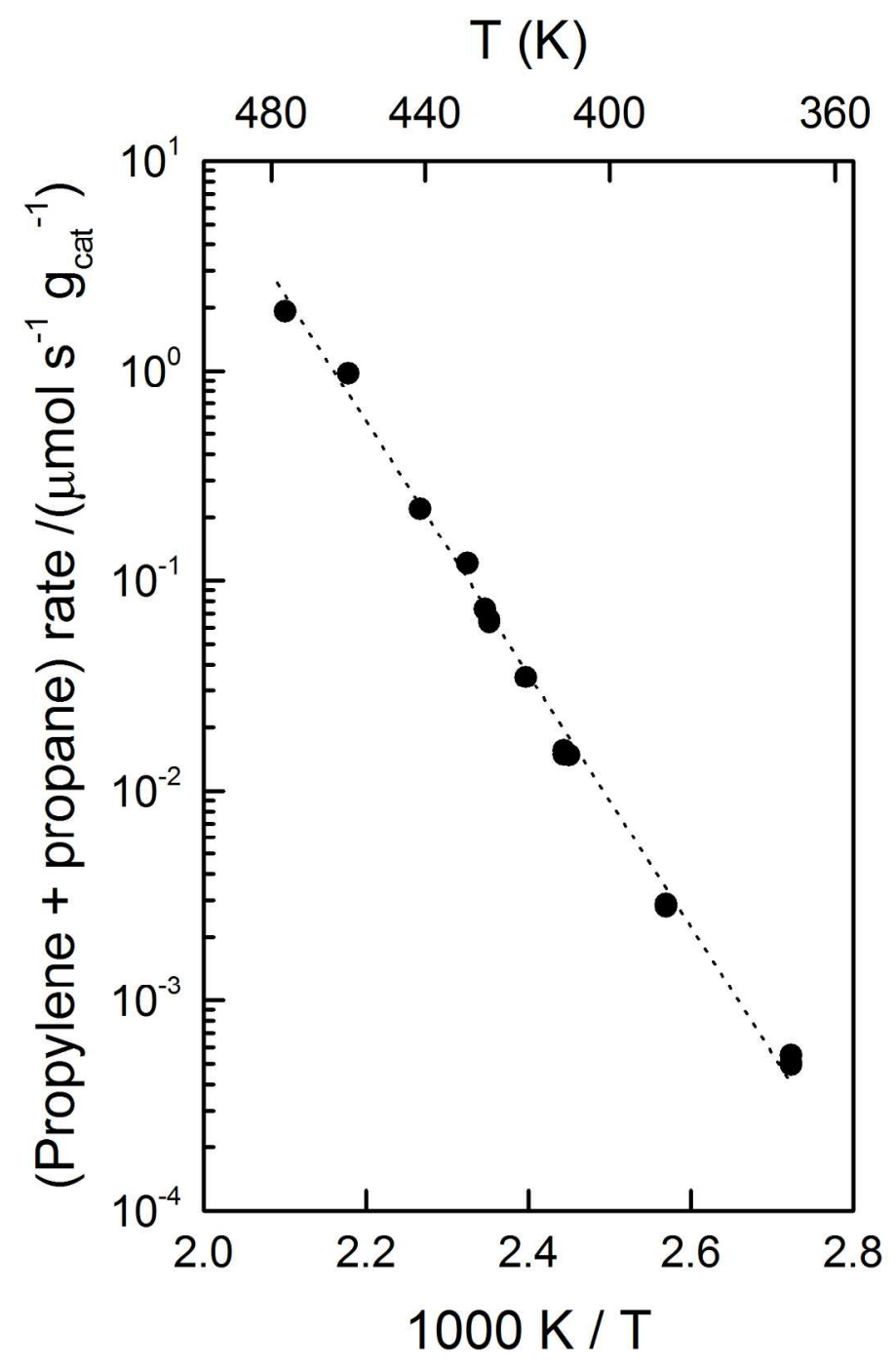

Figure S2. Propanal HDO reaction rate, calculated as the combined formation rate of (propylene + propane), normalized per gram catalyst, as a function of reaction temperature. $\mathrm{P}_{0}=0.26 \mathrm{kPa}$ propanal feed, $81 \mathrm{kPa} \mathrm{H}_{2}, 4 \mathrm{kPa} \mathrm{CH}_{4}$ as an internal standard, balance inert carrier gas, $0.100 \mathrm{~g}_{\text {cat }}, \sim 110 \mathrm{~cm}^{3} \mathrm{~min}^{-1}$ total flow. 


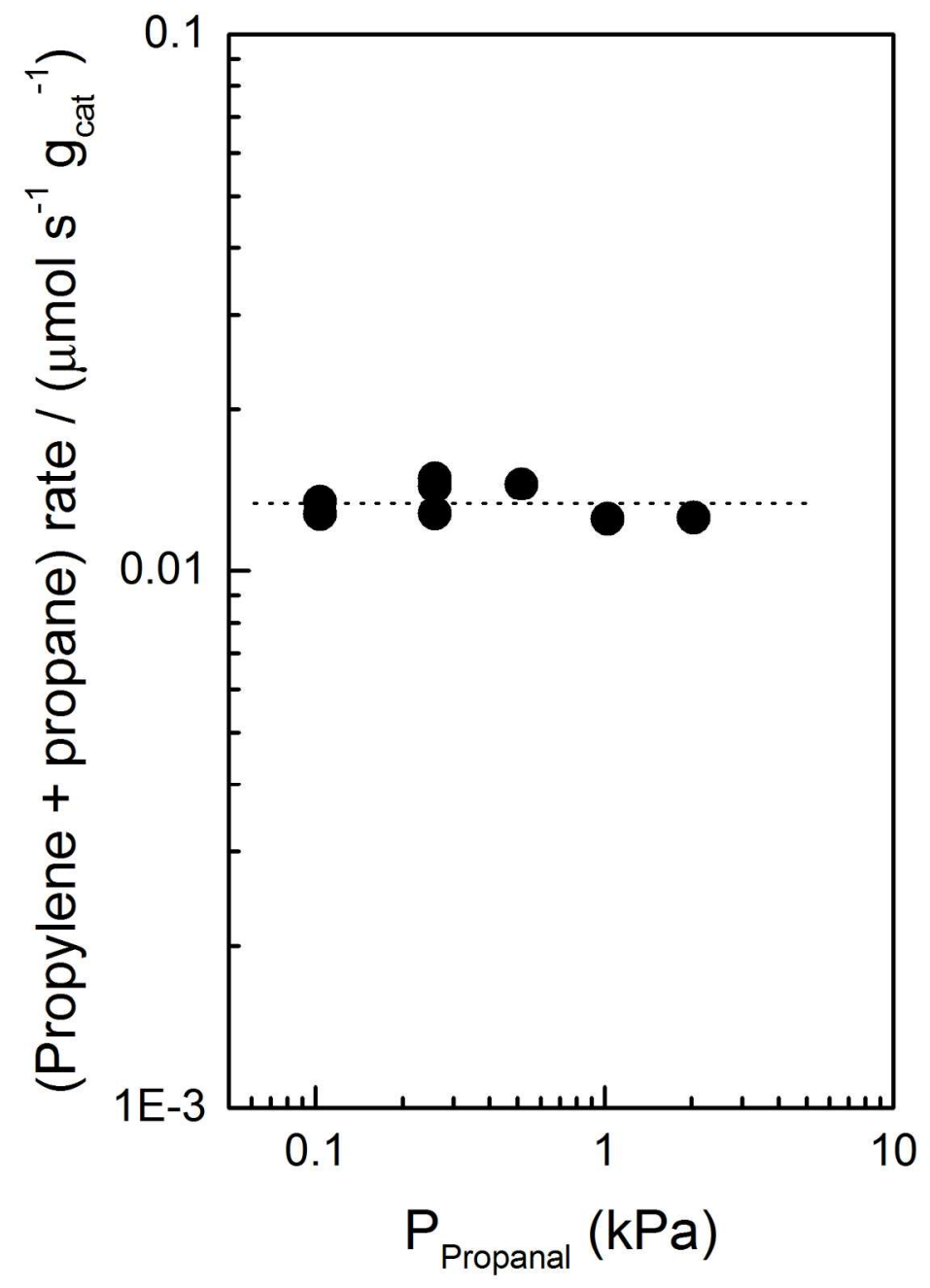

Figure S3. Propanal HDO reaction rate, calculated as the combined formation rate of (propylene + propane), normalized per gram catalyst, as a function of propanal feed pressure. Reactant mixture comprised $81 \mathrm{kPa} \mathrm{H}_{2}, 4 \mathrm{kPa} \mathrm{CH}_{4}$ as an internal standard, and balance inert carrier gas. $\mathrm{T}=369 \mathrm{~K}, 0.100 \mathrm{~g}_{\text {cat }} \sim 110 \mathrm{~cm}^{3} \mathrm{~min}^{-1}$ total flow. 


\section{S.2. Heat and mass transfer calculations}

Mears' Criterion can be used to estimate the existence or negligibility of external heat and external mass transfer calculations when measuring reaction rates. External mass transfer limitations can be neglected if the following inequality is satisfied ${ }^{1}$ :

$$
\frac{r_{o b s} \rho_{b} R n}{k_{c} C_{b}}<0.15
$$

Where $r_{o b s}$ is the observed rate of reaction in $\mathrm{kmol} \mathrm{kgcat}^{-1} \mathrm{~s}^{-1}, \rho_{\mathrm{b}}$ is the catalyst bed density in $\mathrm{kg} \mathrm{m}^{-3}\left(\rho_{\mathrm{b}}=(1-\phi) \rho_{\mathrm{c}}\right.$ where $\phi$ is the bed void fraction and $\rho_{\mathrm{c}}$ is the density of the catalyst, reported to be $760 \mathrm{~kg} \mathrm{~m}^{-3}$ ), $\mathrm{R}$ is the catalyst particle radius in $\mathrm{m}, \mathrm{n}$ is the reactant reaction rate order, $\mathrm{k}_{\mathrm{c}}$ is the external mass transfer coefficient in $\mathrm{m} \mathrm{s}^{-1}$, and $\mathrm{C}_{\mathrm{b}}$ is the reactant bulk concentration in $\mathrm{kmol} \mathrm{m}^{-3}$.

This criterion is the result of expanding a reaction rate expression of the form $r=$ $\mathrm{kC}^{\mathrm{n}}$ with a Taylor series expansion about $\mathrm{C}_{\mathrm{b}}$ and including the first two non-zero terms, assuming a spherical catalyst particle and calculating the criterion for the reaction rate to remain with $95 \%$ of a system entirely at bulk concentration $C_{b}$.

In a similar manner, assuming a spherical particle and an Arrhenius expression for the rate of reaction, the reaction rate can be expanded about $\mathrm{T}_{0}$, the bulk reaction vessel temperature, using a Taylor series and the first two nonzero terms. Using this expansion and setting equal the steady state energy production and convection terms, the criterion for which the reaction rate remains within $5 \%$ of the isothermal case can be solved for, and the criterion is as follows ${ }^{2}$ : 


$$
\frac{|\Delta H| r_{o b s} R E_{a} \rho_{b}}{h R_{g} T_{0}^{2}}<0.15
$$

where $\Delta \mathrm{H}$ is the enthalpy of reaction in $\mathrm{kJ} \mathrm{kmol}^{-1}, \mathrm{E}_{\mathrm{a}}$ is the reaction activation energy in $\mathrm{kJ} \mathrm{kmol}^{-1}, \mathrm{~h}$ is the external heat transfer coefficient in $\mathrm{kW} \mathrm{m}^{-2} \mathrm{~K}^{-1}, \mathrm{R}_{\mathrm{g}}$ is the gas constant $\left(8.314 \mathrm{~kJ} \mathrm{kmol}^{-1} \mathrm{~K}^{-1}\right)$, and $\mathrm{T}_{0}$ is the reaction vessel temperature (369 K). Table $\mathrm{S} 1$ tabulates the relevant parameters and heat and mass criterion.

Table S1. Tabulation of parameters for the calculation of Mears' Criteria for the absence of external heat and mass transfer limitations for IPA $\mathrm{HDO}$ at $369 \mathrm{~K}$ over activated $\mathrm{Mo}_{2} \mathrm{C}$ catalysts.

\begin{tabular}{|c|c|}
\hline Parameter & Value \\
\hline $\mathrm{r}_{\mathrm{obs}}\left(\mathrm{kmol} \mathrm{kgcat}^{-1} \mathrm{~s}^{-1}\right)$ & $1 \times 10^{-7}$ (Above average rate) \\
\hline$\rho_{\mathrm{b}}\left(\mathrm{kgcat} \mathrm{m}^{-3}\right)$ & $532\left(\rho_{\mathrm{c}}=760\right.$, assumed $\left.\phi=0.3\right)$ \\
\hline $\mathrm{R}(\mathrm{m})$ & $\begin{array}{l}1.5 \times 10^{-4} \text { (based off of average mesh size of } \\
400-177 \mu \mathrm{m})\end{array}$ \\
\hline $\mathrm{k}_{\mathrm{c}}\left(\mathrm{m} \mathrm{s}^{-1}\right)^{\mathrm{a}}$ & $1.47 \times 10^{-2}$ \\
\hline $\mathrm{C}_{\mathrm{b}}\left(\mathrm{kmol} \mathrm{m}^{-3}\right)^{\mathrm{b}}$ & $2.98 \times 10^{-4}(0.25 \mathrm{kPa}$ IPA at $110 \mathrm{kPa})$ \\
\hline $\mathrm{n}$ & 0 \\
\hline$\Delta \mathrm{H}\left(\right.$ IPA $->$ Propylene $\left.+\mathrm{H}_{2} \mathrm{O}\right)\left(\mathrm{kJ} \mathrm{kmol}^{-1}\right)$ & 51200 \\
\hline $\mathrm{E}_{\mathrm{a}}\left(\mathrm{kJ} \mathrm{kmol}^{-1}\right)$ & 103000 \\
\hline 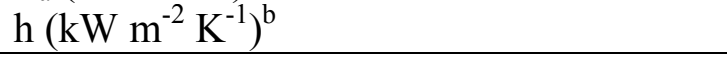 & 1.47 \\
\hline $\begin{array}{l}\text { Mears' Criterion (Mass) } \\
\text { Mears' Criterion (Heat) }\end{array}$ & $\begin{array}{c}0\left(\mathbf{1 . 8 3 \times 1 0 ^ { - 3 }} \text { if assumed } \mathrm{n}=1\right) \\
{\mathbf{2 . 5 3 \times 1 0 ^ { - 5 }}}\end{array}$ \\
\hline
\end{tabular}

${ }^{a}$ Estimated assuming Sh (Sherwood Number) $=\mathrm{k}_{\mathrm{c}}(2 \mathrm{R}) / \mathrm{D}=2$ because Re (Reynolds Number $)=\rho \mathrm{U}(2 \mathrm{R}) / \mu$ $<<1$, where $\rho=$ bulk gas density (Assumed to be $\mathrm{H}_{2}$ at $369 \mathrm{~K}, \rho=6.62 \times 10^{-2} \mathrm{~kg} \mathrm{~m}^{-3}$ ), $\mathrm{U}=$ superficial velocity (total volumetric flow rate $\left(2.85 \mathrm{~cm}^{3} \mathrm{~s}^{-1}\right)$ divided by reaction cross sectional area: tube diameter of $0.01 \mathrm{~m}: \mathrm{U}=3.63 \times 10^{-2} \mathrm{~m} \mathrm{~s}^{-1}$ ), and $\mu=$ gas viscosity (estimated as $\mathrm{H}_{2}$ viscosity at $369 \mathrm{~K}=1.03 \times 10^{-5} \mathrm{~Pa} \mathrm{~s}$ ). $\mathrm{D}$ is gas phase diffusivity, estimated using Chapman-Enskog theory of diffusivity for IPA in $\mathrm{H}_{2}$ at $369 \mathrm{~K}$ $\left(4.68 \times 10^{-5} \mathrm{~m}^{2} \mathrm{~s}^{-1}\right)$.

${ }^{b}$ Estimated by again using $\operatorname{Re}<<1$, so $\mathrm{Nu}$ (Nusselt number) $=\mathrm{h}(2 \mathrm{R}) / \mathrm{k}_{\mathrm{t}},=2$, where $\mathrm{k}_{\mathrm{t}}$ is the thermal conductivity of the reactant fluid, assumed to be $\mathrm{H}_{2}$ at $369 \mathrm{~K}, \mathrm{k}_{\mathrm{t}}=2.2 \times 10^{-4} \mathrm{~kW} \mathrm{~m}^{-2} \mathrm{~K}^{-1}$.

Internal mass transfer limitations were investigated using the Weisz-Prater criterion, which calculates the ratio of the observed rate of reaction to the rate of diffusion: 


$$
C_{W P}=\eta \phi^{2}=\frac{r_{o b s} \rho_{c} R^{2}}{D_{e} C_{A s}}
$$

where $\eta$ is the dimensionless effectiveness factor, $\phi^{2}$ is the dimensionless Thiele modulus, $\mathrm{D}_{\mathrm{e}}$ is the effective diffusivity in $\mathrm{m}^{2} \mathrm{~s}^{-1}\left(\mathrm{D}_{\mathrm{e}}=\mathrm{D} \varepsilon \delta / \tau\right.$, where $\varepsilon$ is the porosity, $\delta$ is the constrictivity, and $\tau$ is the tortuosity, assumed to be average values of $0.35,0.8$, and 6 , respectively), and $\mathrm{C}_{\mathrm{As}}$ is the reactant surface concentration in $\mathrm{kmol} \mathrm{m}^{-3}$, which will equal $\mathrm{C}_{\mathrm{b}}$ because Mears' criterion showed that there were no external mass transfer limitations. Here, $\mathrm{R}$ is the average crystallite size in $\mathrm{m}$, estimated as $1 \times 10^{-6} \mathrm{~m}$ from TEM analysis. If internal mass transfer limitations are negligible, then $\eta \approx 1$ and $\phi^{2}<<1$. If we assume that $\eta=1$ and then solve for $\phi^{2}$, mass transfer limitations will be negligible if in fact $\phi^{2}<<1$. Table S2 tabulates the relevant parameters and calculated criterion.

Table S2. Tabulation of parameters for the calculation of the Weisz-Prater Criterion for the absence of internal mass transfer limitations for IPA dehydration at $415 \mathrm{~K}$ over $\mathrm{O}^{*}$ $\mathrm{Mo}_{2} \mathrm{C}$.

\begin{tabular}{lc}
\hline \multicolumn{1}{c}{ Parameter } & Value \\
\hline $\mathrm{r}_{\mathrm{obs}}\left(\mathrm{kmol} \mathrm{kgcat}^{-1} \mathrm{~s}^{-1}\right)$ & $1 \times 10^{-7}$ \\
$\rho_{\mathrm{c}}\left(\mathrm{kgcat} \mathrm{m}^{-3}\right)$ & 760 \\
$\mathrm{R}(\mathrm{m})$ & $1 \times 10^{-6}$ \\
$\mathrm{C}_{\mathrm{As}}\left(\mathrm{kmol} \mathrm{m}^{-3}\right)$ & $2.98 \times 10^{-4}(0.25 \mathrm{kPa} \mathrm{IPA}$ at $110 \mathrm{kPa})$ \\
$\mathrm{D}_{\mathrm{e}}\left(\mathrm{m}^{2} \mathrm{~s}^{-1}\right)^{\mathrm{a}}$ & $1.16 \times 10^{-7}(\operatorname{assumed~} \varepsilon=0.35, \delta=0.8, \tau=6)$ \\
\hline Calculated Weisz-Prater Criterion $\left(\mathbf{\eta} \phi^{2}\right)$ & $\mathbf{6 . 1 8 \times 1 0 ^ { - 5 }}$ \\
\hline
\end{tabular}

${ }^{\mathrm{a}}$ Knudsen diffusivity was not used because Knudsen number $=\mathrm{k}_{\mathrm{b}} \mathrm{T} /\left(\sqrt{2} \pi d^{2} p L\right)=0.022$. For this calculation, $\mathrm{d}$ is the collision diameter of IPA from Chapman-Enskog theory (4.55 $\AA$ ), $\mathrm{p}$ is atmospheric pressue, and $\mathrm{L}$ is the average pore diameter. The average pore diameter was estimated to be $1 \times 10^{-8} \mathrm{~m}$ from $\mathrm{BJH}$ theory of $\mathrm{N}_{2}$ physisorption isotherms.

We can also calculate a Biot number to show the lack of internal heat transfer resistances. $\mathrm{Bi}=\mathrm{h}(2 \mathrm{R}) / \mathrm{k}_{\mathrm{tc}}$, where $\mathrm{k}_{\mathrm{tc}}$ is the thermal conductivity of the catalyst pellet. Thermal conductivity of Mo and $\mathrm{C}$ are both $0.14 \mathrm{~kW} \mathrm{~m}^{-1} \mathrm{~K}^{-1}$, so this value was assumed for $\mathrm{k}_{\mathrm{c}}$ of $\mathrm{Mo}_{2} \mathrm{C}$. Thus, $\mathrm{Bi}=3.17 \times 10^{-3}$, showing internal heat transfer limitations are 
negligible compared to external heat transfer limitations. These calculations show that the reaction rate is the limiting factor in these kinetic studies. 


\section{S.3. Acetone hydrogenation equilibrium calculations}

Acetone hydrogenation to form IPA is represented below:

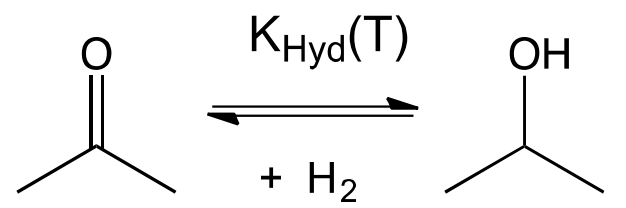

The approach to equilibrium can be calculated from Equation 1 in the text, displayed here again for convenience:

$$
\eta=\frac{P_{I P A}}{P_{\text {Acetone }} P_{H 2}}\left(\frac{1}{K_{H y d}}\right)
$$

where $\eta$ is the calculated approach to equilibrium, $\mathrm{P}_{\mathrm{IPA}}, \mathrm{P}_{\mathrm{Acetone}}$, and $\mathrm{P}_{\mathrm{H} 2}$ are the reactor effluent partial pressures of IPA, acetone, and $\mathrm{H}_{2}$ in atm, respectively, and $\mathrm{K}_{\mathrm{Hyd}}$ is the thermodynamic equilibrium constant of the hydrogenation of acetone to IPA.

A reaction at equilibrium will exhibit $\eta=1$. In order to run differential acetone HDO reactions, assuming that Scheme 1 correctly represents the acetone HDO reaction pathway, it is necessary to feed an equilibrated mixture of acetone/IPA/ $\mathrm{H}_{2}$ over the activated $\mathrm{Mo}_{2} \mathrm{C}$ catalyst in order to observe kinetics of the rate-determining IPA dehydration.

To calculate and feed an equilibrated mixture of acetone and IPA, $\eta=1$, the reaction temperature must be constant and $\mathrm{P}_{\mathrm{H} 2}$ must be chosen a priori. For $\mathrm{T}=369 \mathrm{~K}$ and a predetermined $\mathrm{P}_{\mathrm{H} 2}=81 \mathrm{kPa}$, the equilibrium composition of an acetone/IPA mixture could be calculated according to the following procedure. First, the equilibrium constant of acetone hydrogenation was calculated: 


$$
K_{H y d}^{o}=e^{\frac{-\Delta G_{H y d}^{o}}{R T}}
$$

where $K_{H y d}^{o}$ is the equilibrium constant of acetone hydrogenation to IPA at standard conditions (298 K, $1 \mathrm{~atm}), \mathrm{T}$ is the reaction temperature, $369 \mathrm{~K}, \Delta G_{H y d}^{o}$ is the standard Gibbs free energy of acetone hydrogenation to IPA, $-20.5 \mathrm{~kJ} \mathrm{~mol}^{-1}$, and $\mathrm{R}$ is the ideal gas constant. Plugging in, $K_{H y d}^{o}=3921.5$. It must be noted that both $\eta$ and $\mathrm{K}$ are dimensionless in Equation 1, and the partial pressures in Equation 1 are all normalized by the standard state pressure of 1 atm, thus $\eta$ will only be calculated correctly using Equation 1 if all partial pressures are in atm.

$K_{H y d}^{o}$ was then used to calculate $K_{H y d}(T)$ via the Van't Hoff equation:

$$
\ln \left(\frac{K_{H y d}(T)}{K_{H y d}^{o}}\right)=\frac{-\Delta H_{H y d}^{o}}{R}\left(\frac{1}{T}-\frac{1}{298}\right)
$$

where $-\Delta H_{H y d}^{o}$ is the standard enthalpy of reaction of acetone hydrogenation to IPA, -55 $\mathrm{kJ} \mathrm{mol}^{-1}$, and $\mathrm{T}$ is the reaction temperature, $369 \mathrm{~K}$. Plugging in and solving, $K_{H y d}(T)=$ 54.4 .

Using Equation 1, with $K_{H y d}(T)=54.4, P_{H_{2}}=81 \mathrm{kPa}=0.80 \mathrm{~atm}$, and $\eta=1$, we can solve for $\frac{P_{I P A}}{P_{\text {Acetone }}}=43.46$. Converting using the densities and molar masses of IPA and acetone, this corresponds to a 45.22 volumetric ratio of IPA/Acetone that would be an equilibrated mixture when fed with $81 \mathrm{kPa} \mathrm{H}_{2}$ at $\mathrm{T}=369 \mathrm{~K}$. A similar technique was used to calculate the equilibrium ratio for $\mathrm{P}_{\mathrm{H} 2}=21 \mathrm{kPa}$. 


\section{S.4. Kinetic isotope effect calculations}

The calculation of a primary kinetic isotope effect for IPA dehydration at $369 \mathrm{~K}$ assuming that a $\mathrm{C}-\mathrm{H}$ bond scission is the kinetically relevant step is reported below. For a simple approximation of the kinetic isotope effect, we assume the validity of transition state theory, and the reaction rate constant can be approximated by

$$
k=\frac{k_{b} T}{h} e^{-\frac{\Delta G^{\ddagger}}{R T}}
$$

where $\mathrm{k}$ is the reaction rate constant, $\mathrm{k}_{\mathrm{b}}$ is Boltzmann's constant, $\mathrm{T}$ is the reaction temperature, $\mathrm{h}$ is Planck's constant, $\Delta G^{\ddagger}$ is the change in free energy between the reactants and the transition state, and $\mathrm{R}$ is the ideal gas constant.

We then assume that the $\mathrm{C}-\mathrm{X}(\mathrm{X}=\mathrm{H}, \mathrm{D})$ bond is completely severed in the transition state. The difference between the free energy of the products and the free energy of the reactants is entirely due to the energy of the vibrational frequency of the bond being severed, assuming no other adjacent isotopic bonds vary significantly over the course of the reaction.

We can define the KIE as the ratio of the reaction rate constant of the $\mathrm{C}-\mathrm{H}$ bond scission to the rate constant of the C-D bond scission as follows:

$$
K I E=\frac{k_{H}}{k_{D}}=e^{\frac{\Delta \Delta G^{\ddagger}}{R T}}
$$


where $\mathrm{k}_{\mathrm{H}}$ is the reaction rate constant for the $\mathrm{C}-\mathrm{H}$ bond scission, $\mathrm{k}_{\mathrm{D}}$ is the reaction rate constant for the C-D bond scission, and $\Delta \Delta G^{\ddagger}$ is the difference between the change in free energies for the $\mathrm{C}-\mathrm{H}$ bond scission and the $\mathrm{C}-\mathrm{D}$ bond scission, defined as

$$
\Delta \Delta G^{\ddagger}=\Delta G_{C-D}^{\ddagger}-\Delta G_{C-H}{ }^{\ddagger}
$$

$\Delta \Delta G^{\ddagger}$ is entirely due to the difference in energy of the C-H bond and the C-D bond, and can be calculated as follow:

$$
\Delta \Delta G^{\ddagger}=\frac{1}{2} h[v(C-H)-v(C-D)]
$$

where $v(C-X)$ is the vibrational frequency of the $\mathrm{C}-\mathrm{X}$ bond. This estimate provides an upper bound of the kinetic isotope effect due to the assumption that the $\mathrm{C}-\mathrm{X}$ bond is completely severed in the transition state. Any remaining C-X bond character at the transition state will serve to reduce the magnitude of $\Delta \Delta G^{\ddagger}$, therefore decreasing KIE.

We then assume that the $\mathrm{C}-\mathrm{X}$ bond can be represented as a simple harmonic oscillator with a spring constant, $\mathrm{k}_{\mathrm{s}}$. Its vibrational frequency can be calculated as follows:

$$
v(C-X)=\frac{1}{2 \pi} \sqrt{\frac{k_{S}}{\mu_{C-X}}}
$$


where $v_{\mathrm{C}-\mathrm{X}}$ is the vibrational frequency of the $\mathrm{C}-\mathrm{X}$ bond, $\mathrm{k}_{\mathrm{s}}$ is the spring constant of the vibration, and $\mu_{\mathrm{C}-\mathrm{X}}$ is the reduced mass of the $\mathrm{C}-\mathrm{X}$ bond. $\mu_{\mathrm{C}-\mathrm{X}}$ can be calculated as follows:

$$
\mu_{C-X}=\frac{m_{C} m_{x}}{m_{c}-m_{x}}
$$

where $\mathrm{m}_{\mathrm{i}}$ is the molar mass of element i. Typical $v(C-H)$ values are on the order of $\left(2900 \mathrm{~cm}^{-1}\right)\left(3 \times 10^{8} \mathrm{~m} \mathrm{~s}^{-1}\right)$. We can use this to estimate $v(C-D)$ if we assume that the spring constant of the $\mathrm{C}-\mathrm{X}$ bond, $\mathrm{k}_{\mathrm{s}}$, is indeed a constant. Solving for $\mathrm{k}_{\mathrm{s}}$, writing an equation for both the $\mathrm{C}-\mathrm{H}$ and $\mathrm{C}-\mathrm{D}$ bonds, equating, and rearranging yields the following:

$$
v(C-D)=v(C-H) \sqrt{\frac{\mu_{C-H}}{\mu_{C-D}}}
$$

The theoretical KIE for C-H vs. C-D bond scission at $369 \mathrm{~K}$ was calculated using all of the previous formulae as follows:

$$
\begin{gathered}
K I E=e^{\frac{h[v(C-H)-\nu(C-D)] N_{A}}{2 R T}} \\
=e^{\frac{h v(C-H)\left(1-\sqrt{\frac{7}{13}}\right)}{2 k_{b} T}} \\
e^{\frac{(6.626 e-34 \mathrm{~J} \cdot s)\left(3 e 8 \mathrm{~ms}^{-1}\right)\left(290000 \mathrm{~m}^{-1}\right)\left(1-\sqrt{\frac{7}{13}}\right)}{2\left(1.38 e-23 J \cdot K^{-1}\right)(369 K)}}
\end{gathered}
$$




$$
=4.512
$$

The value reported above provides an upper bound for the $\mathrm{C}-\mathrm{H}$ bond scission KIE at $369 \mathrm{~K}$. Any retention of $\mathrm{C}-\mathrm{X}$ bond character in the transition state would diminish the observed KIE. This observed KIE is also too large to be considered a secondary KIE, typically on the order of KIE $=1.1-1.2$ This means the observed KIE of 1.85 most likely corresponds to $\mathrm{C}-\mathrm{H}$ bond scission as the kinetically relevant step of IPA dehydration over oxygen modified $\mathrm{Mo}_{2} \mathrm{C}$. 


\section{S.5. DTBP titration}

DTBP titrations were performed as described in Section 2.3. Figure S4 shows HDO rates (propylene + propane formation rates) during a representative titration experiment. Extrapolated time to complete deactivation was used to calculate total molar flow rate of DTBP necessary to completely kill the HDO rate; a 1:1 stoichiometry of DTBP: Brønsted acid site was used in order to calculate a site density for rate normalization and turnover frequency (TOF) calculation.

A typical calculation of a HDO TOF is shown below. For one titration experiment, $\sim 0.1 \mathrm{~g}$ of passivated $\mathrm{Mo}_{2} \mathrm{C}$ was activated and used for the titration. The HDO rate (propylene + propane rate) pre-titration was $2.75 \times 10^{-7}$ mol propylene $\min ^{-1} \mathrm{~g}_{\mathrm{cat}}{ }^{-1}$. Multiplying these two yields the rate of production of (propylene + propane), $2.74 \times 10^{-8}$ mol $\min ^{-1}$. As shown in Figure S4, the DTBP titration mixture was introduced and (propylene + propane) production decreased linearly; this decrease was fit with a linear polynomial and this line was extrapolated to the $\mathrm{x}$-intercept, interpreted as the necessary amount of time for the DTBP to eliminate all (propylene + propane) production; this line had an intercept of $2.75 \times 10^{-7} \mathrm{~mol} \mathrm{~min}^{-1} \mathrm{gcat}^{-1}$ and a slope of $-7.01 \times 10^{-9}\left(\mathrm{~mol} \mathrm{~min}^{-1} \mathrm{~g}_{\text {cat }}{ }^{-1}\right)$ $\left(\min ^{-1}\right)$. Dividing the intercept by the opposite of the slope yields $39 \mathrm{~min}$, or $2340 \mathrm{~s}$, of titrant DTBP flow to complete catalyst titration.

The titrant mixture was introduced at a total flow rate of $50 \mu \mathrm{L} \mathrm{h}^{-1}$. This titrant mixture comprised a liquid mixture of $20 \mu \mathrm{L}$ DTBP and $5 \mathrm{~mL}(5000 \mu \mathrm{L})$ IPA. The total titrant DTBP uptake was thus calculated as follows using the density and molar mass of DTBP: 


$$
\begin{aligned}
& \left(\frac{50 \mu \mathrm{L} \text { mixture }}{h r}\right)\left(\frac{0.020 \mathrm{~mL} \text { DTBP }}{5.02 \mathrm{~mL} \text { mixture }}\right)\left(\frac{1 \mathrm{~mL}}{1000 \mu \mathrm{L}}\right)\left(\frac{0.852 \mathrm{~g} \mathrm{DTBP}}{m L \text { DTBP }}\right) \ldots \\
& \left(\frac{\mathrm{mol} \mathrm{DTBP}}{191 \mathrm{~g} \mathrm{DTBP}}\right)\left(\frac{\mathrm{hr}}{60 \mathrm{~min}}\right)\left(\frac{\min }{60 \mathrm{~s}}\right)\left(\frac{2340 \mathrm{~s}}{1}\right)=5.76 \times 10^{-7} \text { mole DTBP }
\end{aligned}
$$

Normalizing the rate of $2.74 \times 10^{-8} \mathrm{~mol} \mathrm{~min}^{-1}$ by the extrapolated total titrant uptake yields $0.0476 \mathrm{~mol} \mathrm{~min}^{-1} \mathrm{~mol} \mathrm{DTBP}^{-1}$. Converting to a per second basis yields $0.000793 \mathrm{~mol} \mathrm{~s}^{-1}$ mol DTBP ${ }^{-1}$. Converting to mmole of (propylene + propane) yields the TOF of 0.793 mmol s${ }^{-1}$ mole DTBP site ${ }^{-1}$ reported in Figure 7 for an activation time of $22 \mathrm{~h}$ under flowing $\mathrm{H}_{2}$.

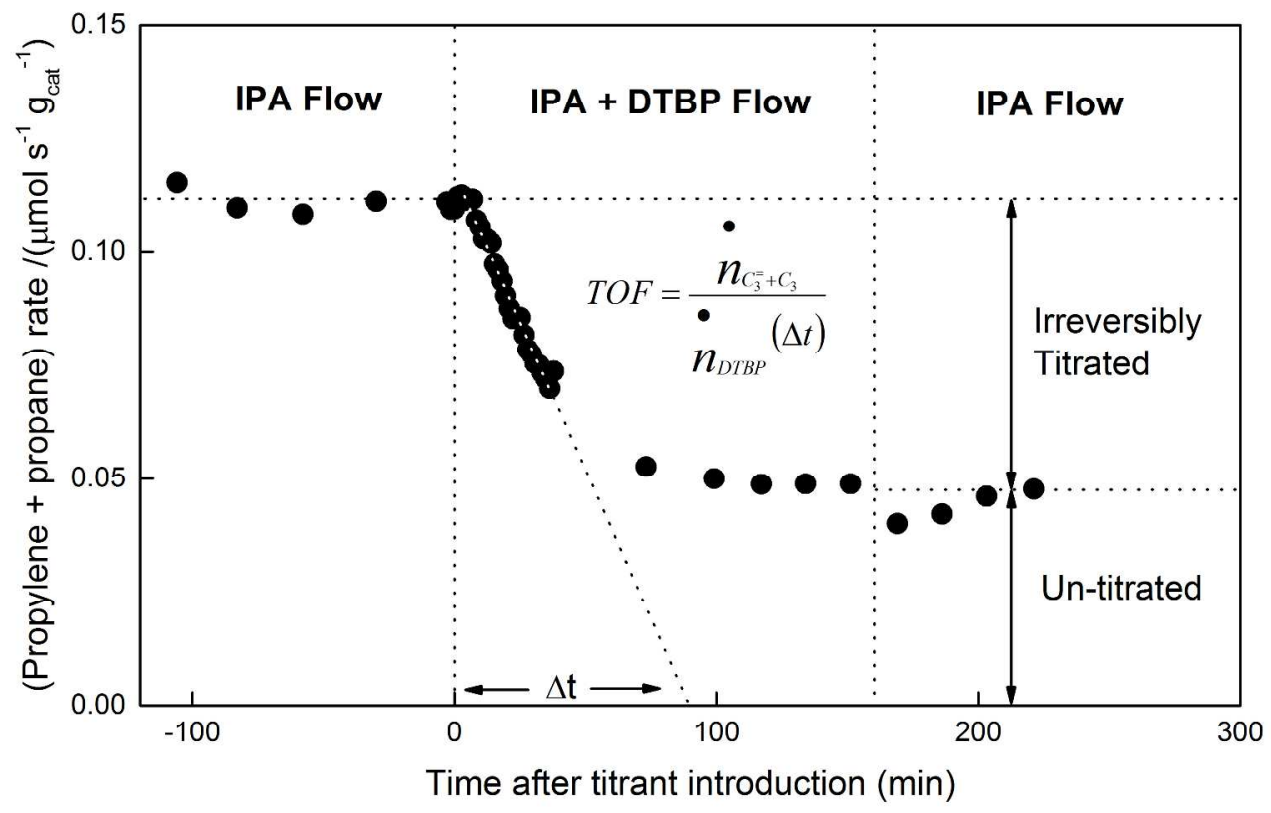

Figure S4. HDO rate (propylene + propane synthesis rate) as a function of time after introduction of the DTBP titrant. $\mathrm{T}=369 \mathrm{~K}, \sim 0.1 \mathrm{~g}_{\text {cat }}$, ambient pressure, acetone/IPA equilibrium mixture pressure $=0.25 \mathrm{kPa}, \mathrm{P}_{\mathrm{H} 2}=80 \mathrm{kPa}, \mathrm{P}_{\mathrm{CH} 4}=4 \mathrm{kPa}$ (internal standard), balance $\mathrm{He}, \sim 1.83 \mathrm{~cm}^{3} \mathrm{~s}^{-1}$ total flow. Titrant flow is an equivalent volumetric flow of acetone/IPA/DTBP with $<1 \times 10^{-3}$ DTBP mole fraction. Acetone/IPA flow resumed at $170 \mathrm{~min}$ after titrant introduction. The diagonal dashed line shows the linear extrapolation used to calculate HDO turnover frequency (TOF). 


\section{References:}

(1) Mears, D. E. Ind. Eng. Chem. Process Des. Dev. 1971, 10, 541-547.

(2) Mears, D. E. J. Catal. 1971, 20, 127-131. 